\title{
Es „crispert“ in der Pflanzenzüchtung
}

\author{
Bernd Müller-Röber ${ }^{1}$
}

Published online: 7 October 2015

(C) Bundesamt für Verbraucherschutz und Lebensmittelsicherheit (BVL) 2015

Wenn wir heutzutage in den Supermarkt gehen, finden wir ein reichhaltiges Spektrum an unterschiedlichen Obst- und Gemüsesorten vor. Und wir freuen uns über Innovationen im Angebot: die kernlose Weintraube, die Wassermelone mit gelbem statt rotem Innenleben, der zehenlose Knoblauch, der uns die Zubereitung in der Küche erleichtert, die Tomate in einer Vielzahl unterschiedlicher Farben und Formen-weiße bis tiefbraune, runde und kleine bis hin zur Coeur de Boeuf. Das alles sind Ausprägungen der Erbinformation, die den genetischen Bauplan dieser Pflanzen darstellen. Andere Eigenschaften-für den Kunden nicht so ohne weiteres erkennbar-betreffen agronomische Charakteristika wie etwa die Resistenz gegenüber viralen, bakteriellen und pilzlichen Krankheitserregern oder gegenüber Fraß-Schädlingen. Auch eine Toleranz gegenüber Umweltstress wie Trockenheit oder Hitze, Ertragsleistung oder die Erntefähigkeit gehören dazu. Schauen wir in unseren eigenen Garten oder in öffentliche Parks, finden wir auch hier eine große Palette an Formen und Farben. Vom Gartenhandel um die Ecke ganz zu schweigen. Auch wenn alte Sorten, beispielsweise von Äpfeln, oft aus nostalgischen Gründen erhalten und gepflegt werden-der Versorgung der Masse unserer Mitbürger dienen sie nicht.

Bernd Müller-Röber

bmr@uni-potsdam.de

1 Universität Potsdam, Karl-Liebknecht-Str. 24-25, 14476 Potsdam, Germany
Innovationen in der Pflanzenzüchtung gibt es seit Jahrtausenden und es gibt keinen Grund anzunehmen, dass sich dies in Zukunft ändern wird. Schon immer ist Pflanzenzüchtung ein von Menschenhand beeinflusstes Eingreifen in den natürlichen Genpool. Durch Selektion von Pflanzen mit gewünschten Eigenschaften erlauben wir es nur einigen von ihnen, ihre Erbinformation in die nächste Generation weiterzutragen, und durch Kreuzung legen wir fest, welche Einzelpflanzen ihr Erbmaterial für die Weitergabe in die nächste Generation austauschen dürfen. Damit eliminieren wir nach und nach unerwünschte Gene aus dem Genpool der Neuzüchtung, und führen neue ein, etwa durch die Kreuzung mit verwandten Wildformen. Auch erzwungene und in der Natur nicht vorkommende Kreuzungen entfernterer Arten haben zu neuen Varietäten geführt. So stellt beispielsweise die recht stresstolerante Getreidepflanze Triticale eine künstliche Kreuzung aus Weizen (lateinischer Gattungsname: Triticum) und Roggen (Secale) dar. Triticale wurde erstmals Ende des 19. Jahrhunderts erzeugt und wird seitdem immer wieder durch Hybridisierung unterschiedlicher Weizen- und Roggen-Sorten in neuen Varianten gewonnen. In Deutschland wird Triticale jährlich bereits auf 400.000 Hektar angebaut, was einem Fünftel der Anbaufläche von Getreide (ohne Mais) entspricht. Sogar im ökologischen Landbau wird Triticale genutzt. Bei dieser Methode akzeptieren wir also die Tatsache, dass Gene artüberschreitend in nicht kontrollierbarer Weise miteinander kombiniert werden.

Die artüberschreitende Kombination von Erbinformation ist nicht der einzige Weg, die genetische Vielfalt $\mathrm{zu}$ erweitern. Seit Jahrzehnten werden 
chemische Agenzien mit mutationsauslösender Wirkung oder physikalische Methoden (zum Beispiel die Behandlung mit radioaktiver Strahlung) dazu verwendet, die pflanzliche DNA zu verändern. Auf diese Weise entstandene Pflanzenvarianten dienen dann wieder als Kreuzungspartner.

Ein Manko dieser Methoden ist aber, dass sie insgesamt als wenig zielgerichtet angesehen werden müssen: Es handelt sich hierbei um Verfahren, mit denen neue Kombinationen von Erbinformation-und damit neue Phänotypen-quasi „gewürfelt“ werden. Wenn hinreichend oft gewürfelt (also Erbinformation kombiniert) wird, findet der Züchter unter den Nachkommen solche, die seinen Vorstellungen einen Schritt näher kommen. Der „Kniffel“ fällt dabei zugegebenermaßen nicht besonders häufig; aber eben häufiger, wenn die Zahl der Kreuzungen erhöht wird.

Da uns über Jahrtausende die Sicht auf die Gene mangels fehlender technischer Möglichkeiten verwehrt war, hat die Pflanzenzüchtung quasi ohne eine genaue Kenntnis der Gene und ihrer Funktionen stattgefunden. Diese Situation hat sich in den letzten drei oder vier Jahrzehnten, seitdem es möglich ist, die Abfolge der Bausteine in Genen zu lesen und die Genaktivität mittels gentechnischer Verfahren zu modifizieren, grundlegend verändert.

Dieser Blick in das genetische Webmuster unserer Kulturpflanzen hat in den letzten Jahren erheblich an Fokus gewonnen. Dank hoch entwickelter Sequenziertechnologien sind wir heute in der Lage, schnell und mit ungewohnter Präzision die Bausteine tausender und abertausender Gene zu erfassen. Damit ergibt sich die Möglichkeit, verwandte Gene in unterschiedlichen Pflanzen auf DNA-Ebene zu identifizieren und Aussagen über deren Funktion zu machen, insbesondere dann, wenn in einer Pflanzenart bereits ein entsprechendes Gen untersucht wurde.

Erst vor wenigen Jahren wurde die Hochdurchsatzsequenzierung eingeführt. Nun steht bereits die nächste technologische Revolution ins Haus: Sie trägt den Namen CRISPR-Cas9, abgekürzt CRISPR, sprich „Crisper“. Worum handelt es sich dabei? Mit wenigen Worten lässt sich das neue molekularbiologische Verfahren kaum erklären. Aber so viel sollten wir uns merken: Es erlaubt das gezielte Ausschalten und Verändern von Genen. Es stellt die abgewandelte Version eines natürlicherweise vorkommenden zellbiologischen Prozesses dar, ist konzeptionell einfach und erfordert für eine erfolgreiche Anwendung nur wenige biologische Komponenten. Und wichtig dabei ist: Durch CRISPR können wir nun genetische Veränderungen in der Pflanze durchführen, ohne dass fremde Gene in die Erbinformation eingeführt werden müssen. In dieser Hinsicht ähnelt die CRISPRMethode der chemischen oder physikalischen Mutagenese, mit dem Unterschied, dass die früheren Methoden völlig zufällig das pflanzliche Erbmaterial veränderten, während mit CRISPR eine hohe Präzision der genetischen Mutagenese möglich wird. Auf diese Weise lassen sich also Gene ausschalten, die einen unerwünschten Einfluss auf das Wachstum oder die Eigenschaften unserer Kulturpflanzen haben.

Wissenschaftler gehen davon aus, dass es mit Hilfe der CRISPR-Technologie schon in Kürze möglich sein wird, Gene innerhalb verwandter Arten auszutauschen. Und hier zeichnet sich ein weiterer entscheidender Vorteil der neuen Technologie gegenüber der traditionellen Artbastardierung ab, wie sie beispielsweise im Falle von Triticale immer wieder praktiziert wird: Während ganze Genome in unkontrollierter Weise kombiniert und dabei auch unerwünschte Gene und Genvarianten übertragen werden, können mit CRISPR gezielt nur die tatsächlich gewünschten Gene eingebracht werden.

Die Pflanzenzüchtung unterliegt einer fortwährenden Weiterentwicklung, und auch in Zukunft werden wir die Entwicklung neuer Technologien zur Optimierung pflanzlicher Produktein ihrem gesamten Nutzungsspektrum-sehen. Die Züchtung neuer Sorten war und ist eine kulturelle Aufgabe ersten Ranges. Noch immer haben viele Mitbürger Bedenken gegenüber modernen Züchtungsmethoden. Es sollte jedoch genau andersherum sein: Indem wir immer mehr Details über biologische Prozesse in Pflanzen wissen, können wir heutzutage viel genauer Züchtung betreiben. Die CRISPR-Technologie spielt dabei eine zentrale Rolle. Zukünftige Entwicklungen unter Verwendung dieser und anderer Technologien versprechen die Bereitstellung von Pflanzen mit verbesserter Nährstoffeffizienz, gesteigerter Toleranz gegenüber Umweltstress oder optimierten, gesundheitsfördernden Eigenschaften. Ein Land wie Deutschland, dessen wesentliche Grundlage des sozialen Fortschritts die Innovation ist, sollte sich den neuen technologischen Entwicklungen in der Pflanzenzüchtung nicht verschließen. 